\title{
ALFABETIZAÇ̃̃O CIENTÍFICA NO CLUBE DE CIÊNCIAS DO ENSINO FUNDAMENTAL: UMA QUESTÃO DE INSCRICุÃO'
}

\author{
Moisés Alves de Oliveira*
}

RESUMO: Neste trabalho são apresentadas algumas reflexões acerca do processo de alfabetização científica em atividades práticas de um clubinho de ciências. A questão que motivou a pesquisa foi: Quais mediações articulam a alfabetização científica e a realidade das coisas? A perspectiva teórico-metodológica valeu-se do conceito latouriano de inscrição e da perspectiva etnográfica não moderna. A análise foi desenvolvida em duas etapas: A) uma descrição considerando o efeito da exposição visual como inscrição direta, que mantém dicotomizadas as concepções de natureza e conhecimento; B) levando-se em conta as mediações que se articulam como inscrição para tornar possível um conhecimento científico específico. Finalizamos propondo que a realidade existe quando a inscrição torna inseparáveis os meios que produzem do que é produzido, segundo um maneirismo particular.

Palavras-chave: Alfabetização Científica; Inscrição; Clubinho de Ciências.

\section{SCIENTIFIC LITERACY AT A SCIENCE CLUB OF ELEMENTARY SCHOOL: A MATTER OF INSCRIPTION}

ABSTRACT: This article shows some reflections about the scientific literacy process in practical work at a science club. The question that motivated the research was: What kind of intervention articulates the scientific literacy and the reality? The perspective of this work was based in Latour's concept of inscription and a non-modern ethnographic perspective. The analysis happened in two stages: A) a description considering that the effect of a visual exhibition as direct inscription, keeps the nature and knowledge conceptions separate; B) by considering the interventions that are articulated as inscriptions to enable a specific scientific knowledge. We finalize the article proposing that the reality exists when the inscription makes inseparable the means that produce from what is produced, according to a particular way.

Keywords: Scientific Literacy; Inscription; Science Club. 
Este trabalho analisa alguns aspectos que constituem os jogos de convencimento no processo de alfabetização científica em um clubinho de ciências, para alunos do ensino fundamental, em que o experimento de laboratório é o elemento central. A motivação para a divulgação surgiu da necessidade de responder a questão que me move, já há alguns anos, acerca do problema de como é constituída a natureza das coisas e também pelo interesse do entendimento do que motiva a alfabetização científica nos laboratórios escolares, a ponto de inscrevê-los como os pontos centrais do empirismo científico de acesso à realidade. O laboratório didático, tomado em hipótese por sua ênfase no caráter realista de representação ${ }^{2}$ (SILVA, 2003) e de exposição, com uma vontade de expor o espectador ao fato, permite estudar juntamente os mecanismos que produzem a alfabetização científica no laboratório escolar como representação, numa concepção que faz a ponte, que relaciona o real dado pela natureza ou pelas teorias, e as formas pelas quais esse real se torna fato para nós. Nesse sentido, a representação pode ser tomada como inscrição, naquilo que ela puder representar como marcas, traços, equipamentos, registros que dão visibilidade ao conhecimento.

A perspectiva teórico-metodológica que me permitiu lançar um olhar renovado sobre a questão da inscrição como traço central no processo de alfabetização científica nos laboratórios de ciências, foram os Estudos Culturais das Ciências, mais especificamente, os Estudos de Laboratório (KROPF; FERREIRA, 1998; LATOUR; WOOLGAR, 1997; LATOUR, 1983, 1993; KNORR-CETINA, 1981) e os conceitos da etnografia do campo aberto (GOTTSCHALK, 1998; WALLACE, 2004).

Os estudos da inscrição pela ótica cultural têm forte influência dos estudos realizados por Bruno Latour (LATOUR; WOOLGAR, 1997), segundo uma perspectiva relativista (CEPEDA, 2000) e adquirem importância neste trabalho por apresentarem, em vez da ideia de ruptura entre epistemologia (o que se diz da realidade) e ontologia (a realidade), algo diverso, que assume uma análise do caráter contingencial com que são produzidas as condições de possibilidade dos fatos científicos experimentais, sempre produtos ulteriores das atividades de laboratório.

Para Latour; Woolgar (1997), a inscrição pode ser entendida como movimentos tanto discursivos quanto materiais, que são necessários para mediar a ocorrência de uma ação, considerando-se o jogo de deslocamento de cada participante, para modificar e deslocar seus vários e contraditórios interesses (LATOUR, 2001; LAW, 1992). Por essa concepção, é possível pensar na inscrição como produzida por meio de um sistema de relações que, na sua própria formação, constituiu o alinhamento de atuações que possibilitam uma determinada alfabetização científica, em detrimento de outras.

O apagamento de outras possibilidades é discutido por Derrida (1999, p. 295) como um sistema linguístico em que quanto mais é articulada uma língua - um texto, uma inscrição - mais rápido ela traduz, mais racional e menos musi- 
cal ela se torna "e por isso menos perde com ser escrita, melhor ela exprime a necessidade". A inscrição, pelo seu caráter sintético, movimenta-se com facilidade, permitindo novas translações e articulações, ao mesmo tempo em que mantém intactas algumas formas de relações que constrói e reconstrói a cultura/tradição escolar específica do laboratório. A inscrição tem o sentido de estabelecer os registros e documentos gerados durante o experimento que podem desencadear uma nova discussão sobre o assunto. Portanto, não há $a$ alfabetização científica de laboratório antes da inscrição. ${ }^{3}$ A vantagem da utilização deste conceito, para usar os termos de Latour, está na possibilidade de descrever "algumas atividades de laboratório sem que seja necessário dar conta de todo um processo anterior" (LATOUR; WOOLGAR, 1997, p. 45).

Alguns pesquisadores têm sublinhado o aspecto plural da inscrição, tornando central a dimensão multifacetada das práticas materiais das inscrições institucionais e políticas no contexto do laboratório escolar. Para Lenoir (1997, p. 52),

nós não podemos compreender esses processos [inscrição literária] se prestarmos atenção no caráter dos dispositivos de inscrição em si, ou na indefinida cadeia de significantes que eles produzem; ao contrário, nós devemos investigar o jogo de disputas que une os significantes a interpretações específicas.

Latour, por sua vez, alerta para as dificuldades de explicar a inscrição que produz e reproduz o alfabeto específico do laboratório, recorrendo a uma definição modernista de construção técnica - ou, menos ainda, a uma construção social, dadas as negociações, as alianças, as bifurcações, as contingências que Latour (2001, p. 323) chama de "passagem da atenção do idioma modernista para o não-modernista".

Essa passagem para o idioma não moderno (LATOUR, 1994) será considerada, para os objetivos deste trabalho, como aqueles defendidos por Wortmann; Veiga-Neto (2001, p. 18), em que as pessoas envolvidas nos Estudos Culturais da Ciência recusam as

categorias que opõem conhecimento científico a outras produções culturais [...] não se atribui à comunidade científica, sob nenhuma hipótese, autoridade para falar para as demais como uma voz unitária, ou dotada de qualquer tipo de superioridade advinda de suas práticas epistêmicas.

Isto não quer dizer que a ciência escolar não exercite um estatuto próprio de alfabetização. O que vejo como possibilidade é poder superar o sentimento de estratificações de culturas pelo estudo de como os conhecimentos e sentimentos são postos em ação e atingem códigos de validade e de riqueza, que produzem as vontades da inclusão, exclusão, da autoexclusão e da reinclusão, como que havendo algo como dentro e fora, em cima e embaixo, etc. Trazer à consciência a possibilidade de articular diferentes posições, permite romper com 
o entendimento de subordinação dos conhecimentos científicos produzidos na escola como, unitariamente, voz reprodutora dos conhecimentos e comportamentos produzidos em outras instâncias. Isso abre uma nova perspectiva de olhar o que se faz nos laboratórios escolares, pois desloca o interesse do conhecimento-em-si, internalizante e condicionado ao trabalho da própria área, para a alfabetização como produto de inscrições, anunciando, somente ao final, que qualquer um que queira ser um verdadeiro cientista e detentor dos métodos científicos deve passar por suas bancadas.

O conceito de inscrição ajudou a estudar a alquimia da transmutação da matéria da química em fragmentos de domínio das considerações, motivação, cuidados de si, habilidades motoras e do modus faciendi específico do aluno e do professor que atuam no laboratório. $\mathrm{Na}$ próxima seção, apresento uma síntese dos aspectos centrais que constituem a perspectiva metodológica adotada na constituição e análise dos eventos estudados.

\section{METODOLOGIA}

Do ponto de vista ferramental, a metodologia seguiu as técnicas de coleta e análise apresentadas por Graue (2003); Walch (2003), Adler (1994), Latour (1985), Gottschalk (1998) e Costa (2002) no que apresentam como descrição narrativa e da observação participante. Utilizei os métodos de geração de dados por meio da tomada de notas, gravações, fotos e entrevistas para posterior produção do registro de dados, em que fiz a construção de uma descrição tomando excertos do que foi observado nas atividades de laboratório do clubinho de ciências, coordenado pela Prof. ${ }^{a}$ Bulla ${ }^{4}$, cujas atividades eram desenvolvidas no período vespertino para alunos que permaneciam em tempo integral na escola, cerca de seis alunos em idade entre 7 e 10 anos, do Colégio São José em São Leopoldo (RS), colégio privado e administrado pelas Irmãs Franciscanas da Penitência e da Caridade Cristã. Localizado em região privilegiada da cidade, atende alunos considerados de boa renda familiar.

Do ponto de vista etnográfico, há de ser considerada a percepção da visão cultural presente, as subjetividades, os movimentos retóricos, os jogos de poder, a autoridade da voz, a presença de entidades não humanas e, sobretudo, a ideia da impossibilidade de qualquer uma das "técnicas" funcionarem de forma desvinculada dos jogos de poder que as constituem (GOTTSCHALK, 1998, CALDEIRA, 1988). A perspectiva do campo aberto da metodologia etnográfica está vinculada a indissociabilidade de cada atuante ao próprio movimento do evento. Dessa maneira, a cultura da alfabetização científica pressupõe uma tradição que implica texto, potência, movimento e motivo, mas sem haver qualquer primeiro "motivo" imóvel. É uma atualização concebida dentro de uma progressão hierárquica em que humanos e não humanos produzem suas múltiplas formas de beleza e contemplação do mundo. Para Wallace (2004), os eventos se arti- 
culam como presença, lançados no mundo e abertos para o mundo. Não há indivíduos fechados que vez ou outra se abrem, o ente é lançado no mundo e sempre aberto e disponível a ele. Nessa concepção não há mundo, não há coisa, não há ser fora do próprio exercício de ser.

Atuei nesse campo durante quatro meses, duas vezes por semana. Foram gravadas 20 horas de conversas em fita cassete. As conversas gravadas consistiram, particularmente, dos momentos de maior discussão entre alunos e professora, enquanto executavam as diversas atividades do clubinho de ciências. Além das gravações, eram realizadas conversas (algo como: entrevistas não estruturadas) com a professora e com os alunos para ajudar na compreensão de pontos centrais das atividades observadas. Para fazer o registro de questões e movimentos que pudessem escapar ao registro em áudio, fiz anotações permanentes em um diário de campo, posto que esse tipo de etnografia exige uma sensibilidade que vai além

das tarefas essenciais de coleta, organização, interpretação, validação e comunicação de dados, a etnografia pós-moderna exige também que seu autor permaneça constantemente e criticamente atento a questões tais como a subjetividade, os movimentos retóricos e os problemas da voz, poder, política textual, limites a autoridade, asserções de verdade, desejos inconscientes e assim por diante. (GOTTSCHALK, 1998, p. 207)

Tal estratégia "metodologia do campo aberto" está de acordo com a especificidade do local de trabalho e com a sensibilidade do pesquisador etnográfico em uma perspectiva não moderna. Tentei buscar, em vez de uma descrição da "realidade" cultural dos eventos, uma evocação da experiência produzida da própria presença do observador no campo, com o intento de promover uma compreensão por elementos não transcendentais, por meio de um trabalho de recontextualização, de costuras teóricas e de ensaios, naquele sentido dado por Larrosa (1994) de buscar novas metáforas, novos sentidos.

A análise de um material construído desta forma resultou em uma descrição. Uma descrição com o sentido de síntese. A síntese é, então, uma maneira de conferir algum rigor à descrição na busca por estabelecer alguns nós na rede de relações que constituem esse trabalho, mas não pode ser mais do que o seu porta-voz; ela - a descrição - representa a trama, mas não é a trama, tem vida própria, mas não pode viver só.

Para os objetivos desse trabalho, o campo e a metodologia estão articulados com a exigência de um autor auto-reflexivo presente no texto. A descrição não moderna admite, e por vezes exige a escrita na primeira pessoa do singular.

Vamos à terceira etapa que se constitui em descrever como foi elaborado o recorte para facilitar a comunicação das ideias acerca de como a inscrição funciona na produção da alfabetização científica. 


\section{PRODUZINDO UM RECORTE PARA A ANÁLISE}

O objetivo é preocupar-me com eventos e com atuantes capazes de produzir algum tipo de materialização documentável no laboratório, por meio de instrumentos. Estes instrumentos estão relacionados às estruturas que produzem situações observáveis e permitem o acompanhamento dos movimentos subsequentes. São os instrumentos chamados dispositivos de inscrição ${ }^{5}$.

Seguindo sob a égide de uma descrição dos eventos havidos nos rituais do clubinho de ciências, um em particular motivou a escrita deste trabalho, por representar mais claramente a concepção que tenho de alfabetização científica como o momento em que se observa o "resultado" da relação entre um sistema concreto e um aluno: o aluno Gabriel (9 anos) e um experimento em que se observou a presença de ar no solo, por meio de um artifício, um dispositivo de inscrição que chamarei de máquina de fazer bolhas. Farei a descrição em duas etapas, como segue.

\section{0 ar sempre existiu e se inscreveu diretamente para Gabriel}

Essa primeira descrição constitui um momento em que uma inscrição direta, explícita e sistemática apresentou-se com certa autonomia em relação a Gabriel, que parecia ter tirado as conclusões acerca da existência do ar diretamente e sem intermediários da própria "natureza" do evento.

No ambiente do laboratório, a Prof. ${ }^{a}$ Bulla dispunha de algo que é o mais eficiente dos recursos retóricos para falar da natureza das coisas: a exposição visual. Ver com os próprios olhos é como ir dos textos para o real; é ir para onde tudo se resolve; é ir para o local em que o texto supostamente é feito. Vejamos, por um excerto do diário de campo, o que ocorre quando a professora dá aos alunos algo por ver:

160402CCEP03 - 14:12 - As atividades do dia se iniciaram com algumas explicações da Prof. ${ }^{a}$ Bulla acerca da terra; logo em seguida ela pegou na prateleira um vulcão feito de argila e colocou dentro uma porção generosa de bicarbonato de sódio, depois, com aquele ar de naturalidade do personagem cinematográfico 007, quando interpretado por Mike $\mathrm{Myers}^{6}$, adicionou vinagre, resultando em uma erupção de espuma. Ouvi muitos Hóoooos! Seguido por várias inferências dos alunos, um deles, o Gabriel, antecipava os acontecimentos com grande alegria. Suas respostas e participação destacavam-se dos demais. Gabriel levantou a mão e com o sorriso batendo nas orelhas disse:

— "Prof.! Então a rocha derrete e vira areia!" Fiquei empolgado, como, tomando como inscrição a formação de montanhas a partir de erupções vulcânicas, Gabriel pôde dizer convicto que a erosão se dava por que a chuva iria "derretendo" a montanha e se transformava em areia? Aquela era, para mim, um observador que não possuía as informações históricas do grupo, uma situação de aprendizagem incidental e implícita na qual Gabriel fez por si mesmo, na relação com o experimento do vulcão, extrapolações para o processo de erosão, o que se pode chamar, se considerado o pensamento de Soares, (2004) de alfabetização científica. Seguido a esse evento veio a per- 
gunta de uma aluna (Patrícia, 10 anos): - “ Professora, como tem minhoca na terra que veio do vulcão?” A pergunta desencadeou uma discussão sobre como é possível ter vida na terra. Gabriel, mais uma vez irradiante disse: — "Dentro da terra tem ar pra minhoca respirar!"

A professora rapidamente pegou um aquário, retirou a terra e despejou um pouco d'água, em seguida recolocou um torrão ressequido que estava no aquário. As crianças, e eu também, vimos que se desprendiam bolhas e, voilà, estava comprovado, havia ar dentro da terra. Pudemos ver com os próprios olhos, diretamente na natureza. Aquele experimento relâmpago inscreveu a prova inquestionável. Este é um acontecimento interessante, pois parece fazer desaparecer qualquer intermediário que possa estar por trás do que pode ser chamado de resultado final: a natureza das coisas.

Por um tempo fiquei ensimesmado olhando as bolhas se desprenderem do interior daquele punhado de terra. Este é o ponto forte do laboratório, ele dá a ideia que avança por meio dele, mas não necessariamente nele, de um pulo só, da teoria à natureza. Ser capaz de fazer este salto, como o fez Gabriel, é um indício de uma alfabetização científica muito específica, produzida no interior das práticas laboratoriais, visto que este aluno demonstrou ser capaz de desenvolver habilidades do uso das informações em outros registros científicos.

Fiquei visivelmente feliz com as surpreendentes descobertas do "aprendiz de cientista". Após as atividades do clubinho, comentei com a professora que reações como aquelas apresentadas por Gabriel me deixavam contente, pois estabeleciam algo próximo ao que Larrosa chama de experiência (BONDÍA, 2001), como algo que nos passa e deixa marcas que entendemos como importantes. Mas, a professora seguiu contando que aquele aluno estava há tempos no clubinho de ciências e já havia visto aquelas experiências várias vezes: “[...] Porque Gabriel é o quarto ano que tá nessa caminhada, ele não é aluno de agora [...] é um somatório do que a gente vem trabalhando com o tempo, não é de agora.".

Eu fiquei paralisado na frente da professora, um tanto constrangido por ser professor há tantos anos e ser surpreendido por certa "inocência" do olhar. Como pude não pensar que muita água havia corrido sob a ponte? Mas como diz Serres (1999), a intuição vem como um flash. Ora, está justamente nisso a maquinaria da produção da alfabetização como um salto da natureza para o conhecimento articulado. Há um "esquecimento" da história produtiva - por mais presente que ela esteja - ofuscada, talvez, pela "luz do flash", que age poderosamente, direcionando o entendimento para um local continente e específico. Aquela explosão de conhecimento era a camada mais aparente de um longo processo de articulação e rearticulação de informações. O que parecia para mim uma experiência privilegiada e instantânea, passou rapidamente a ser vista como um jogo de articulações. Por certo que Gabriel entendeu melhor o fenômeno após muitos contatos. Mas naquele instante, era como se ele não tivesse já algumas vezes pensado sobre aquele evento e o conceito de erosão, de mistura e de dissolução, viessem como flashes em sua mente. Era perceptível para o meu olhar 
alienígena a textura modulável, a permanência do enunciado que se inscreveu, quando a natureza passou do mundo ao sujeito (Gabriel), fazendo com que o sujeito fosse reportado ao mundo da natureza, em um sistema de referências contínuas que se dá não pela região de contato, mas pelos extremos - sujeito de um lado, natureza de outro.

Ter sido surpreendido pela fala da professora quanto à existência de uma história, um jogo enunciativo por trás das evidências de alfabetização que presenciei, foi como parar de olhar por um instante para a figura gestáltica que somente permite ver os extremos pato e coelho como formas preexistentes à criação. A surpresa, o estranhamento, motivou rever aquelas práticas pelos seus detalhes constituintes, sob a ótica relativista proposta por Latour; Woolgar (1997). Tal estratégia é para entender a maneira com que uma inscrição torna-se modulável a ponto de produzir uma distinção entre o conceito e a substância original.

\section{A inscrição é a modulação do ar e 0 torna possível como alfabetização científica}

Neste segundo olhar, vou analisar o evento do aparelho de fazer bolhas preocupado em entender como se produzem os procedimentos, as inscrições que devem ser olhadas e experimentadas como alfabetização científica.

A demonstração feita pela Prof. ${ }^{a}$ Bulla às crianças parece, como vimos acima, derrubar o argumento de que a natureza é o produto final de um longo empacotamento de fatos. É realmente difícil dizer que há inscritores ali funcionando, ao menos da maneira como foi anunciado acima, em que se diz do dispositivo de inscrição como algum tipo de instrumento capaz de produzir uma exposição visual em um texto científico. (LATOUR, 2000). Mas há uma diferença importante entre mostrar e ver, que fica subsumida diante do fascínio de ver o aparelho de fazer bolhas funcionando. Ver acontecer não é como estar diante de um livro didático de ciências, repleto de figuras concretas em que ocorrem separações de fases; estávamos no local onde a separação ocorreu diante dos nossos olhos, em meio a vários frascos, terra e água que lambuzavam a bancada. Isso é, sem dúvida, mais do que a figura de um livro ou a palavra da professora. O processo de representação que se construiu no laboratório funcionava como uma localidade marcada pelo interesse em fazer um ambiente que fosse uma réplica da natureza, que fosse capaz de contar uma história e ser agradável ao olhar curioso dos alunos, ou seja, um ambiente capaz de mostrar o que se quer ver e não outra coisa. Um ambiente projetado para ser adequado à vida humana, tudo ao alcance de alguns passos e de alguns olhares (LENOIR, 1997, p. 56). Ao ouvir a explicação da Prof. ${ }^{a}$ Bulla, senti como se estivesse no passeio turístico citado por Ruiz (2001, p. 168), em que a natureza foi projetada segundo os interesses políticos naquele microambiente escolar. Esse foi um momento interessante, que me fez perceber a existência do processo de manipulação que está 
por trás daquilo que será exposto aos alunos. Tal como os momentos que antecedem ao espetáculo, os bastidores nos quais se produzem as representações e os significados daquilo que deve e pode ser visto.

Ao invés de acreditar que podemos ver com os próprios olhos, diretamente na natureza, o aparecimento de bolhas de ar, vamos nos atentar para as camadas que estão por trás do que pode ser chamado de resultado final, a última camada de um longo processo ocorrido no laboratório dias antes.

A ideia de olhar para os processos de inscrição suscitou uma questão simples. Se ocorresse da professora, em vez de ter pegado um torrão ressequido do aquário, onde outrora havia minhocas, ter posto na água um pedaço úmido de argila de modelar, que estava lá, na prateleira próxima, o resultado seria o mesmo?

Dias antes não havia terra no aquário do laboratório, e tiveram que ir até a horta - que eles cultivam - coletar um pouco, tiveram de encontrar uma enxada, uma pá, algo para transportar a (a)mostra; a professora, com base nas suas experiências, selecionou uma parte de terra adequada para aquele tipo de experimento (criação de minhocas) que depois de abandonado num canto do laboratório produziu os torrões. Pensar por essa ótica continua a fazer as bolhas resultantes saltarem tão rapidamente, sem intermediários da natureza, para os sentidos? Ou seria uma porta-voz, uma representante? As bolhas já não parecem mais tão naturais quanto antes, é preciso que pessoas com habilidades específicas e instrumentos estejam presentes para que seus fenômenos naturais tornem-se convincentes. Aquele pedaço de solo endurecido no aquário não seria capaz, por si só, de dar qualquer informação acerca do conceito de separação de fases e de como as minhocas respiram em seu interior. Foi preciso criar um ambiente adequado, repleto de mediações modulares para que a exposição visual, ao final, se tornasse tão poderosa.

Pensar nos enunciados que estavam atuando naquele momento deixa a cabeça às voltas. O clubinho de ciências é uma das atividades que funciona para manter ocupadas as crianças que permanecem o dia todo na escola, enquanto os pais trabalham. Estabelecer atividades cientificas que fossem interessantes era um dos objetivos em que a Prof. ${ }^{a}$ Bulla tinha que investir muitos esforços, caso contrário, as crianças rapidamente ficariam entediadas. Para tanto, tinha que haver no laboratório vários instrumentos, amostras, curiosidades, negociados anteriormente e postos em prontidão como aliados.

Esta é uma forma de pensar perigosa para aqueles que pretendem a pesquisa etnográfica como mecanismo de trazer claridade de entendimento aos eventos. Não se pode esperar desatar nós górdios por essa perspectiva. Quanto mais adentro na escola, mais complexas e articuladas vão se tornando as bolhas de ar vistas no aparelho de fazer bolhas que, para funcionar bem, tornar-se independente, precisou articular-se com os interesses e a política de manter a atenção das crianças e da ideia de que é a camada mais fina e externa de um complexo arranjo de manipulações. Tampouco necessita estar articulado de forma 
permanente e dependente. Não precisa funcionar como se fosse a própria natureza que estivesse ali, agindo por si só. É, até mesmo, o oposto. É justamente por ser algo profundamente articulado e móvel na teia de interesses que, as bolhas, o conceito de separação de fases, a professora, o Colégio São José, os alunos, os laboratórios de Biologia e de Química se tornam fortes, ou não, na comunidade onde atuam. Lembro, porém, que este trabalho não pretende alçar olhares para além de um caso. É, como diz Lenoir (2004, p. 14), “um microestudo, específico e contingente". Esta é uma limitação anunciada, o poder do olhar deste texto não irá ultrapassar a própria capacidade do observador.

Neste segundo exercício de observar o aparelho de fazer bolhas, foram levantadas algumas possibilidades de como o olhar é influenciado pelos contingentes eventos do campo, de tal forma que não se pode mais dizer tão facilmente de uma natureza alfabetizada sem prestar atenção aos movimentos enunciativos que inscrevem-se pelo caminho. Faço, na seção seguinte, uma tentativa de costurar essas duas maneiras de olhar, valendo-me das contribuições de Latour (2001), quando esse traz uma provocativa proposição acerca de como estas estratégias de acomodar os fatos em camadas bem sobrepostas influencia nossa maneira de ver a ciência escolar de um lado e a natureza de outro:

\footnotetext{
Os filósofos da ciência gostam de lembrar-nos, como se isso fosse o epítome do bom senso, que não devemos confundir nunca questões epistemológicas (nossa representação do mundo) com questões ontológicas (a realidade do mundo). Infelizmente, se seguirmos o conselho dos filósofos, não compreenderemos nenhuma atividade científica, pois confundir aqueles dois domínios supostamente separados é precisamente o que os cientistas fazem a maior parte do tempo (LATOUR, 2001, p. 110).
}

\section{BUSCANDO UMA CONTEXTUALIZAC̣ÃO}

$\mathrm{Na}$ seção anterior, busquei os elementos contingenciais e inseparáveis da condição de estar no campo de pesquisa, como produtores dos recortes que apresentei acima. Fiz isso para tornar possível alguma análise específica, não toda a produção cultural ocorrida no laboratório, mas apenas os eventos que constituíram um momento de alfabetização científica pelo aparelho de fazer bolhas, utilizando o conceito de inscrição como articulação de um intermediário que possibilitou certa autonomia das conclusões do Gabriel, e minha também, acerca da existência do ar diretamente da própria "natureza" do evento, como disse acima, pelo eficiente recurso retórico para falar da natureza: a exposição visual.

Agora, é preciso valer-me do quanto a ideia de inscritor é relativa para poder dar continuidade à minha argumentação.

Em um laboratório didático, tal como os encontrados nas escolas, onde os recursos instrumentais são escassos e a retórica tem grande força, o aparelho de fazer bolhas teve papel importante como um inscritor do texto científico. Texto, aqui, é tomado como um conjunto de enunciados específicos 
que produzem uma cultura de laboratório dentro de uma cultura escolar (COLLINS; GREEN, 1992), no qual o modo como todos os atuantes interagem afetam a natureza dos seus conteúdos, ao qual Street (2003) chama de eventos de letramento $^{7}$, tomado como não neutro e que supera a noção de alfabetização como aquisição de conhecimentos e habilidades. No entanto, a alfabetização, como estritamente conectada a qualquer ocasião em que algo escrito funciona como interação dos participantes no processo interpretativo, não funciona completamente neste caso, no laboratório escolar a inscrição passa por equipamentos, fenômenos visuais e por pessoas que produzem efeitos de sentido que são gravados e transportados de forma específica. Dessa maneira a inscrição é tomada como um processo anterior à escrita, como sendo a porção aparente de um processo de estabelecimento de ordem que visa articular o texto como ausência dos intermediários, deixando pelo caminho tudo que lhe era suplementar (DERRIDA, 1999).

Assim, a noção de inscrição passa a ter sentido dentro das condições específicas deste caso, em que a visualização das bolhas estabeleceu uma relação direta com a natureza (LATOUR; WOOLGAR, 1997). Esta ponderação é importante, pois, naquele ambiente trabalhou-se com algumas crianças que ainda não dominavam completamente a leitura e a escrita, mas que participavam ativamente junto às outras, no evento em que buscava-se dar sentido ao conceito de separação de fases, ao mesmo tempo em que ocorria um processo de alfabetização do discurso científico conforme explicitamente declarou a Prof. ${ }^{a}$ Bulla: " [...] é uma forma de trabalhar né, um jeito que tu faz de o aluno ver e aprender o que é importante ele aprender e fazer aquilo que a gente tá aprendendo, só da boca pra fora não dá, aqui tem experiência [...] e aí tu vai mostrando, e aí eles não esquecem mais.".

A Prof. ${ }^{a}$ Bulla adotava uma perspectiva de caminhar segundo os interesses que surgissem da própria atividade experimental em que a imagem realista era quem atuava como inscritora da ordem natural. Portanto, parece necessário propor uma ampliação das noções de inscrição e alfabetização para dar conta das traduções: conceito $\Longleftrightarrow$ natureza, produzida pela intermediação do aparelho de fazer bolhas e pela presença da Prof. ${ }^{a}$ Bulla como uma porta-voz, tanto do próprio aparelho quanto do modus faciendi. "Eu perguntei para eles o que era o método científico, e eles responderam que era ir para a biblioteca pesquisar. Aí eu disse, vou ensinar para vocês o que é $\mathbf{O}$ método científico. E aí a gente propôs essa atividade [...]".

A Prof. ${ }^{a}$ Bulla seguia estabelecendo o método científico de pesquisa e também quem era a porta-voz autorizada para falar do método. A política da ciência inscreve-se no momento da construção de uma mentalidade de conscientização científica. Porém, naquele evento, não se pode falar de seus enunciados sem levar em conta, também, a própria presença do equipamento, das descrições e imagens como atuantes circunstancialmente ativos no evento em que ambos, humanos e não humanos sofreram modificações, enquanto permutavam competências (LATOUR, 2001). 
De qualquer maneira, em última análise, quando se fala em alfabetização ou inscritor, fala-se apenas da prova visual mais aparente e passível de circular em um meio específico e não dos inúmeros intermediários e interesses que atuaram para possibilitá-la. É esta a beleza, para utilizar a expressão de Latour (2000), que há em utilizar o conceito de inscritor, pois ele nos permite entender como o conteúdo vai diretamente àquilo que lhe dá sustentação sem precisar ter em conta um grande número de intermediários. Bruno Latour diz que não se deve fazer "pressuposições sobre o material de que o instrumento é feito. Ele pode ser um aparelho concreto como o telescópio, mas também pode ser feito de material menos tangível. Uma instituição de estudos [...]" (LATOUR, 2000, p. 114). Por este enfoque, o laboratório escolar, quando está produzindo uma maneira específica de alfabetização, funciona como um inscritor, não importando a complexidade e as agonísticas em que os eventos estiveram envolvidos para produzir uma figura, uma imagem, um texto passível de ser visualizado ou de circular por outros ambientes e eventos.

\section{CONSIDERAÇÕES FINAIS: A INSCRIC̣ÃO COMO MANUFATURA DA ALFABETIZAC̣ÃO CIENTÍFICA}

Agora já tenho uma maneira de olhar a alfabetização científica nos laboratórios escolares; entendi com Gabriel, que os pensamentos que brotam em nossas mentes como ideias, passam por um longo trabalho manual. É então, articulando "inscritores", que produzimos por trás uma natureza das coisas, constituída na articulação, na necessidade de pôr em movimento vários interesses que em princípio não estão relacionados, mas quando atuam juntos transformam-se mutuamente, ao mesmo tempo em que fortalecem suas conexões e suas referências, dando mais realidade, mais originalidade aos conteúdos, às pessoas e aos instrumentos no invólucro chamado laboratório. Tanto mais conectados quanto mais eficientes os intermediários de inscrição!

A realidade existe quando a inscrição torna inseparáveis os meios que produzem do que é produzido. A alfabetização científica pode, então, ser tomada como inscrição, como marcas, traços, equipamentos, registros que dão visibilidade ao conhecimento, tão valioso para os professores. Mas é também um jogo de poder anunciativo ao materializar a ideia de que qualquer um que queira ser um verdadeiro cientista e detentor dos métodos científicos deve passar pelas bancadas de um laboratório.

Fazer parte por alguns meses do clubinho de ciências e, poder contar parte da experiência que tive, não serviu para mostrar o quanto há de política por trás das pretensas artes finais de ensinar a praticar a ciência, creio que "todos" sabem disso. O que me preocupa é que ir ao campo "aberto" fazer pesquisa, mostra uma riqueza que põe em xeque e faz questionar a pretensão purificada da alfabetização científica como algo capaz de fazer o que promete: conscientizar e 
emancipar. No limite, a alfabetização científica específica do laboratório, nas condições descritas para esse trabalho, é construída por meio de uma intrincada rede de negociações, de interesses por credibilidade e por equipamentos destinados a apagar o caráter construído dos eventos científicos. O que me preocupa e me faz pensar, é quanto essa pretensão é o produto final, um simulacro que direciona o olhar e não permite ver além das próprias contingências e especificidades com as quais foram criadas, da mesma maneira como fui surpreendido pela minha própria simulação de eficiência do Gabriel. O que me preocupa e me assusta é que todo o investimento na promessa que vai à frente da alfabetização seja uma poderosa arma de sujeição. Podemos estar "todos" equivocados em acreditar na promessa da ciência escolar da emancipação consciente?

\section{NOTAS}

${ }^{1}$ Este trabalho foi originalmente apresentado no V Congresso Internacional de Educação. São Leopoldo, UNISINOS, 2007.

2 A representação como uma forma de alfabetização científica, distingue-se neste trabalho de estudos, acerca da imagem da ciência, em termos de inscrição, ou seja, como registros que possam ser imediatamente utilizados em outros registros. Silva (2003, p. 53) diz que as "duas noções começam a se separar [...], na medida em que a noção de imagem está inscrita numa epistemologia realista. O conceito de imagem está ligado aos de imitação, reprodução, mimese, reflexo, analogia, ícone. Todos eles expressando alguma forma de conexão intrínseca, necessária - uma correspondência entre a imagem e a realidade que ela supostamente reflete, reproduz, imita [...] o real nunca é questionado como sendo, ele próprio, um produto da representação. Em contraste, a noção de representação, tal como utilizada na análise cultural, está centrada nos aspectos de construção e de produção das práticas de significação. A imagem reflete a realidade; a imagem "é" a realidade. (isto é: a realidade que importa)".

3 Discuto o problema da inscrição como estando por trás da produção dos fatos científicos em Oliveira (2008).

4 O nome da atuante foi alterado. A expressão atuante tem importância neste trabalho, por proporcionar que humanos e não-humanos sejam simetricamente considerados nos exames das práticas laboratoriais. Dentro de uma rede de relações os atuantes estão inscritos por métodos de tradução e autorizados a representar ou utilizar as articulações singulares da rede da qual fazem parte. $\mathrm{Na}$ concepção de Latour o ator só pode ser entendido por intermédio de sua atuação, ou seja quando outros atores da rede são "modificados, perturbados ou criados pela personagem em apreço” (LATOUR, 2001, p. 143).

5 Diz Latour que um "dispositivo de inscrição é qualquer estrutura - sejam quais forem seu tamanho, sua natureza e seu custo - que possibilite uma exposição visual de qualquer tipo" em uma situação de prática de laboratório. Não são quaisquer instrumentos que são capazes de produzir a inscrição, e também não se pode definir a priori quais serão estes instrumentos; a natureza da inscrição está implicada nas articulações possíveis no interior de uma prática específica (LATOUR, 2000, p. 112).

6 Filme: Austin Powers: O Espião Irresistível. Realizado por Jay Roach, EUA, 1999, Cor - 95 min. Com: Mike Myers, Heather Graham e Michael York.

7 Tomarei o conceito de letramento como indissociável do conceito de alfabetização, conforme o que preconiza Soares (2004). 


\section{REFERÊNCIAS BIBLIOGRÁFICAS}

ADLER, P. A.; ADLER, P. Observational techniques. In: DENZIN, N. K., LINCOLN, Y. S. (Ed.). Handbook of qualitative research. Thousand Oaks: Sage, 1994. p. 377-392.

BONDÍA, J. L. Notas sobre a experiência e o saber de experiência. Revista Brasileira de Educação, Rio de Janeiro, n. 19, p. 20-28, jan./abr., 2002.

CALDEIRA, T. P. R. A presença do autor e a pós-modernidade em antropologia. Novos Estudos: Rio de Janeiro, v. 21, p. 133-157, 1988.

CEPEDA, A. H. A conexão racional: ruptura e associação na construção da objetividade das Ciências Sociais. 2000.159 f. Tese (Doutorado em Sociologia) - Programa de Pós-Graduação em Sociologia e Antropologia, Universidade Federal do Rio de Janeiro, Rio de Janeiro.

COLLINS, E.; GREEN, J. Learning in classroom settings: making or breaking a culture. In: MARSHALL, H. (Ed.). Redefining student learning: roots of educational restructuring. Norwood: Ablex, 1992. p. 59-85.

COSTA, M. V. A escola tem futuro? Rio de Janeiro: DP\&A, 2003.

DERRIDA, J. Gramatologia. $2^{a}$ ed. São Paulo: Perspectiva, 1999.

GIROUX, H. A. Praticando estudos culturais nas faculdades de educação. In: SILVA, T. T. (Org.). Alienígenas na sala de aula. Petrópolis: Vozes, 1995. p. 85-103.

GOTTSCHALK, S. Postmodern sensibilities and ethnographic possibilities. In: BANKS, A.; BANKS, S. Fiction and social research. London: Sage, 1998. p. 206-226.

GRAUE, M. E.; WALSH, D. J. Investigação etnográfica com crianças: teorias, métodos e ética. Lisboa: Fundação Calouste Gulbenkian, 2003.

KNORR-CETINA, K. D. The manufacture of knowledge: an essay on the constructivist and contextual nature of science. New York: Pergamon Press, 1981.

KROPF, S. P.; FERREIRA; L. O. A prática da Ciência: uma etnografia no laboratório. História, Ciências, Saúde - Manguinhos, Rio de Janeiro, v. 4, n. 3, p. 589-597, nov. 1997.

LARROSA, J. Tecnologias do Eu e educação. In: SILVA, T. T. (Org.). O sujeito da educação: estudos foucaultianos. Petrópolis: Vozes, 1994. p. 35-87.

LATOUR, B. Ciência em ação: como seguir cientistas e engenheiros sociedade afora. São Paulo: UNESP, 2000.

Give me a laboratory and I will raise the world. In: MULKAY, M.; KNORR-CETINA,

K. (Ed.). Science observed: perspectives on the study of science. London: Sage, 1983. p. 141-170. - Jamais fomos modernos. Rio de Janeiro: Ed. 34, 1994. . L'Anthropologie des sciences. Culture Technique, Paris, v. 14, p. 4-9. 1985.

. Pasteur on lactic acid yeast: a partial semiotic analysis. Configurations, v. 1, n. 1, p. 129-146,

1993.

2001.

A esperança de pandora: ensaios sobre a realidade dos estudos científicos. Bauru: EDUSC,

LATOUR, B.; WOOLGAR, S. A vida de laboratório: a produção dos fatos científicos. Rio de Janeiro: Relume Dumará, 1997.

LAW, J. Notes on the theory of actor-network: ordering, strategy and heterogeneity. Systems Practice, v. 5, n. 4, p. 379-393, 1992.

LENOIR, T. A ciência produz̨indo a natureza: o museu de história naturalizada. Epistéme, Porto Alegre, v. 2, n. 4, p. 55-72, 1997.

NOS, 2004.

Instituindo a Ciência: A produção cultural das disciplinas científicas. São Leopoldo: UNISI-

McROBBIE, A. Pós-marxismo e estudos culturais. In: SILVA, T. T. (Org.). Alienígenas na sala de aula. Petrópolis: Vozes, 1995. p. 39-60.

OLIVEIRA, M. A. O laboratório didático de química: uma micronarrativa etnográfica pela ótica do conceito de articulação. Ciência \& Educação. São Paulo, v. 14, p. 101-114, 2008.

RUIZ, M. D. Trivialidade e transcendência, usos sociais e políticos do turismo cultural. In: LARROSA, J.; SKLIAR, C. (Org.). Habitantes de babel: política e poéticas da diferença. Belo Horizonte: Autêntica, 2001. p. 163-185. 
SERRES, M. Luzes: cinco entrevistas com Bruno Latour. São Paulo: Unimarco, 1999.

SILVA, T. T. O currículo como fetiche: a poética e a política do texto curricular. Belo Horizonte: Autêntica, 2003.

SOARES, M. Letramento e alfabetização: as muitas facetas. Revista Brasileira de Educaşão. Rio de Janeiro, n. 25, p. 5-17, jan./fev./mar./abr. 2004.

STREET, B. What's "new" in new literacy studies? Critical approaches to literacy in theory and practice. Current issues in comparative education. New York, v. 5, n. 2, may, 2003.

WOLLACE, S. Towards a symmetric (social-material) ethnography: theorizing innovation and conservation practices in health care. In: SOCIETY FOR SOCIAL STUDIES OF SCIENCE AND EUROPEAN ASSOCIATION FOR THE STUDY OF SCIENCE AND TECHNOLOGY Conference, 2004, Paris. Anais eletrônicos... Paris, 2004

WORTMANN, M. L. C.; VEIGA-NETO, A. Estudos culturais da ciência \& educação. Belo Horizonte: Autêntica, 2001. 
